\title{
Preservation of the spleen improves survival after radical surgery for gastric cancer
}

\author{
J P Griffith, H M Sue-Ling, I Martin, M F Dixon, M J McMahon, A T R Axon, \\ D Johnston
}

\begin{abstract}
One hundred and ninety five consecutive, potentially curative resections for adenocarcinoma of the stomach were performed in one surgical department between 1970 and 1989: 76 patients underwent gastrectomy with splenectomy and 119 gastrectomy without splenectomy. Operative mortality was $12 \%$ after gastrectomy with splenectomy, but only $2 \cdot 5 \%$ after gastrectomy without splenectomy $(\mathbf{p}<0 \cdot 05)$. Postoperative complications were also significantly more common when splenectomy was combined with gastrectomy $(41 \% \quad v \quad 14 \%, \quad \mathrm{p}<0.01)$. Cumulative five year survival was $45 \%$ after gastrectomy with splenectomy, compared with $71 \%$ after gastrectomy alone $(p<0.01)$. When the results of the two groups of patients were compared, stage for pathological stage, no evidence was found that splenectomy improved survival. Application of Cox's proportional hazards model, which makes allowance for other variables such as the $T$ and $\mathbf{N}$ stages, showed that splenectomy had an adverse influence on patients' survival. Splenectomy does not benefit the patient and its routine use in the course of radical resections for carcinoma of the stomach should be abandoned.

(Gut 1995; 36: 684-690)
\end{abstract}

Keywords: spleen, splenectomy, gastric cancer.

It is widely assumed and confidently asserted at scientific meetings, that advances in mere surgical technique have reached their limit and have little further part to play in improving the results of treatment of gastrointestinal cancer, further progress being held to lie predominantly in the domain of the oncologist or geneticist. Such sweeping assumptions have been vigorously challenged by Heald $e t a l,{ }^{1}$ who reported striking advances in the prevention of local pelvic recurrence of rectal cancer by the use of better surgical techniques and by McArdle and Hole, ${ }^{2}$ who stated that if average surgical standards (in colorectal cancer) could be raised to the level achieved by the best surgeons, the improvement in patients' outcome might equal or surpass anything currently achieved by means of adjuvant therapy.

Improvements in surgical technique may take the form of more radical resections, as in the case of extended (R2) lymphadenectomy for gastric cancer. Paradoxically, significant advances may occasionally result from the adoption of less radical rather than more radical surgical methods, which incorporate new knowledge of the value to the host of the structures thus preserved. For example, the increasing understanding of the part played by the spleen in the immunological defences of the body and in the prevention of sepsis prompted this reappraisal of the value of routine removal of the spleen, en bloc with the stomach, in the course of radical, potentially curative resection for gastric cancer. Our hypothesis was that splenectomy performed routinely in these circumstances would probably do the patient more harm than good.

\section{Methods}

\section{Patients and operative procedures}

Between January 1970 and December 1989, 493 consecutive patients with adenocarcinoma of the stomach were treated in the University Department of Surgery of the General Infirmary at Leeds. In 207 of them it proved possible to perform a radical, potentially curative resection, in which all visible tumour was removed and the proximal and distal resection margins were free of tumour on microscopic examination. Of the 207 patients, 76 underwent total gastrectomy with splenectomy, 21 total gastrectomy without splenectomy, and 98 subtotal gastrectomy without splenectomy. The remaining 12 patients underwent IvorLewis oesophagogastrectomy and are not considered further in this analysis. Fourteen of 76 patients who underwent total gastrectomy with splenectomy also underwent distal pancreatectomy.

Since 1978, the standard surgical approach has consisted of wide gastric resection with a radical (R2) lymphadenectomy, in which the second tier of lymph nodes (N2), beyond the perigastric nodes (N1), is removed. ${ }^{3}$ In those patients who underwent a radical (R2) total gastrectomy, this entailed the removal of the spleen and distal pancreas, as advocated by the Japanese. In the early 1980s, however, we noticed an increase in operative mortality and morbidity in patients who had their spleen and pancreas resected. We therefore modified our approach in the mid 1980s to conserve the spleen and pancreas wherever possible, while still maintaining a radical lymph node clearance. These two organs were still resected, however, if the tumour was close to or directly invading either the tail of pancreas or splenic hilum.

All total gastrectomy procedures were accompanied by Roux-en-Y reconstruction 
TABLE I Details of the 195 patients who underwent potentially curative resection for gastric cancer

\begin{tabular}{|c|c|c|c|c|}
\hline \multirow{3}{*}{$\begin{array}{l}\text { Patients }(n) \\
\text { Age (years, median with interquartile } \\
\text { range) }\end{array}$} & \multicolumn{2}{|c|}{ Gastrectomy with splenectomy } & \multicolumn{2}{|c|}{ Gastrectomy alone } \\
\hline & 76 & & 119 & \\
\hline & $68(61-74)$ & & $68(60-74$ & \\
\hline $\operatorname{Sex}(M: F$ ratio $)$ & $2 \cdot 3: 1$ & & $\begin{array}{l}1.5: 1 \\
154\end{array}$ & \\
\hline Operative procedure & $T G$ and $S x$ & TG, Sx, and PX & TG alone & STG \\
\hline Patients (n) & 62 & & 21 & 98 \\
\hline \multicolumn{5}{|l|}{ Tumour stage* } \\
\hline I (\%) & $18(29)$ & $4(29)$ & $10(48)$ & $45(46)$ \\
\hline II $(\%)$ & $9(15)$ & $4(29)$ & $4(19)$ & $23(23)$ \\
\hline III $(\%)$ & $35(56)$ & $6(42)$ & $7(33)$ & $30(31)$ \\
\hline
\end{tabular}

^ 1987 Unified TNM staging system. ${ }^{4} \mathrm{TG}=$ total gastrectomy, $S \mathrm{TG}=$ subtotal gastrectomy, $\mathrm{Sx}=$ splenectomy, $\mathrm{Px}=$ pancreatectomy. Note that patients who underwent splenectomy had more advanced tumours than patients who did not undergo splenectomy.

with a 40-50 cm Roux loop of jejunum. Polya reconstruction was normally used after subtotal gastrectomy. The tumours were staged in accordance with the 1987 unified International TNM classification for gastric cancer. ${ }^{4}$ Table I gives further details of the patients. It is important to note that patients who underwent gastrectomy with splenectomy had more advanced tumours, on average, than patients who did not undergo splenectomy.

\section{Follow up}

Patients were reviewed every three months for one year and six monthly thereafter at a special gastric follow up clinic. If recurrence of tumour was suspected clinically, an upper gastrointestinal endoscopy and either ultrasonography or computed tomography were performed. Cause of death was ascertained from our own and general practitioners' records, and from the Yorkshire Regional Cancer Registry. The cause of death was unclear in one patient in whom a postmortem examination was not performed. Only one of 195 patients was lost to follow up.

\section{Statistical methods}

Differences in tumour stage and postoperative complications were analysed by means of $x^{2}$ and Fisher's exact tests. Cumulative survival was calculated by the life table method of Kaplan and Meier, after exclusion of operative deaths. ${ }^{5}$ Survival was also calculated with operative deaths included. Differences in survival between patients who had undergone splenectomy and patients who had not undergone splenectomy were analysed by the log rank method. Cox's proportional hazards model ${ }^{6}$ was used to assess the prognostic value of independent variables.

\section{Results}

\section{Operative mortality}

Overall mortality within 30 days of operation was $6 \%$. Mortality was $12 \%$ (nine of 76 ) after total gastrectomy with splenectomy, $0 \%$ ( 0 of 21) after total gastrectomy alone, and 3\% (three of 98) after subtotal gastrectomy alone (Table II). Operative mortality was significantly greater $(p<0.05)$ among patients who underwent gastrectomy with splenectomy $(12 \%)$ than among patients who underwent gastrectomy without splenectomy $(2.5 \%$, three of 119). Table III shows the causes of death. Sepsis was an important cause of death after gastrectomy with splenectomy (seven of 76, $9 \%$ ), whereas fatal sepsis was uncommon after gastrectomy without splenectomy (one of 119 , $1 \%, \mathrm{p}<0.05)$.

Fourteen patients underwent distal pancreatectomy in addition to splenectomy: operative mortality in these patients was $21 \%$ (three of 14), while mortality was $10 \%$ (six of 62 ) after gastrectomy and splenectomy without pancreatectomy (NS).

Three other patients died between one and three months after operation: one after subtotal gastrectomy and two after total gastrectomy and splenectomy. Three month operative mortality was thus $7 \cdot 5 \%$ : $14 \%$ after gastrectomy with splenectomy and 3\% after gastrectomy without splenectomy $(p<0.01)$.

\section{Postoperative morbidity}

Forty eight patients (25\%) developed significant postoperative complications. The incidence of complications was $41 \%$ after gastrectomy with splenectomy, 5\% after total gastrectomy alone, and $16 \%$ after subtotal gastrectomy (Table IV). Gastrectomy with splenectomy was associated with significantly greater postoperative morbidity than gastrectomy without splenectomy $(41 \% \quad v \quad 14 \%$ respectively, $p<0 \cdot 01)$. Much of the morbidity was attributable to anastomotic leakage and to septic complications, whether intra-abdominal or pulmonary.

\section{Survival}

Influence of splenectomy on survival without allowing for TNM stage - cumulative five year survival was $61 \%$ (Table II). Among patients who underwent gastrectomy (total or subtotal) without splenectomy, five year survival was $71 \%$, whereas among patients who underwent

TABLE II Influence of splenectomy on outcome of potentially curative resection for gastric cancer

\begin{tabular}{|c|c|c|c|c|c|}
\hline & \multirow{2}{*}{$\begin{array}{l}\text { All cases } \\
T G \text { or } S T G+/-S x\end{array}$} & \multirow{2}{*}{$\begin{array}{l}\text { Splenectomy } \\
T G, S x+I-P x\end{array}$} & \multicolumn{3}{|l|}{ No splenectomy } \\
\hline & & & $T G$ and $S T G$ & $T G$ & $S T G$ \\
\hline \multirow{2}{*}{\multicolumn{6}{|c|}{$\begin{array}{l}\text { Patients ( } \mathrm{n}) \\
\text { Operative mortality }\end{array}$}} \\
\hline & & & & & \\
\hline $\begin{array}{l}1 \text { month }(\%) \\
3 \text { months }(\%)\end{array}$ & $12(6)$ & $9(12)^{\star}$ & $\begin{array}{l}3(2 \cdot 5)^{\star} \\
4(3) t\end{array}$ & $\begin{array}{l}0(0) \\
0(0)\end{array}$ & $\begin{array}{l}3(3) \\
4(4)\end{array}$ \\
\hline $\begin{array}{l}3 \text { months (\%) } \\
\text { Postoperative complications (\%) }\end{array}$ & $\begin{array}{l}15(7 \cdot 5) \\
48(25)\end{array}$ & $\begin{array}{l}11(14) \dagger \\
31(41) \ddagger\end{array}$ & $\begin{array}{c}4(3) \dagger \\
17(14) \ddagger\end{array}$ & $\begin{array}{l}0(0) \\
1(5)\end{array}$ & $\begin{array}{c}4(4) \\
16(16)\end{array}$ \\
\hline \multirow{2}{*}{$\begin{array}{l}\text { Five year survival } \\
\text { operative deaths excluded (\%) } \\
\text { operative deaths included (\%) }\end{array}$} & & & & & \\
\hline & $\begin{array}{l}61 \\
55\end{array}$ & $\begin{array}{l}45 \dagger \\
39 \ddagger\end{array}$ & $\begin{array}{l}71 \dagger \\
67 \ddagger\end{array}$ & $\begin{array}{l}78 \\
78\end{array}$ & $\begin{array}{l}69 \\
65\end{array}$ \\
\hline
\end{tabular}

${ }^{\star} \mathrm{p}<0.05 ; \mathrm{tp}<0.01 ; \ddagger \mathrm{p}<0.001$. Abbreviations as Table I. 
TABLE III Details of the 12 patients who died within 30 days of operation

\begin{tabular}{lllll}
\hline Procedure & $\begin{array}{l}\text { Age and } \\
\text { sex }\end{array}$ & Stage & Cause of death & $\begin{array}{l}\text { Time to } \\
\text { death (days) }\end{array}$ \\
\hline TG, Sx, and Px & $73 \mathrm{~F}$ & I & Unknown & 10 \\
TG, Sx, and Px & $80 \mathrm{M}$ & I & Septicaemia & 3 \\
TG, Sx, and Px & $64 \mathrm{~F}$ & III & Anastomotic leak and sepsis & 10 \\
TG and Sx & $79 \mathrm{M}$ & I & Haemorrhage & 1 \\
TG and Sx & $71 \mathrm{M}$ & III & Anastomotic leak and sepsis & 14 \\
TG and Sx & $73 \mathrm{M}$ & III & ARDS and septicaemia & 14 \\
TG and Sx & $81 \mathrm{M}$ & III & Anastomotic leak and sepsis & 27 \\
TG and Sx & $62 \mathrm{M}$ & III & Septicaemia & 16 \\
TG and Sx & $61 \mathrm{M}$ & III & Bronchopneumonia & 28 \\
STG & $78 \mathrm{~F}$ & I & Stroke & 13 \\
STG & $62 \mathrm{~F}$ & III & Renal failure & 3 \\
STG & $65 \mathrm{~F}$ & III & Septicaemia & 13 \\
\hline
\end{tabular}

ARDS $=$ Adult respiratory distress syndrome. Other abbreviations as Tables I and II.

gastrectomy with splenectomy, five year survival was only $45 \%(\mathrm{p}<0.01$, Fig 1$)$. When operative deaths were included in the analysis, the difference in five year survival between the two groups of patients - those with or without splenectomy - was even greater: $67 \%$ after gastrectomy alone, but only $39 \%$ after gastrectomy with splenectomy $(\mathrm{p}<0.001)$ : overall five year survival was then $55 \%$. Five year survival after total gastrectomy without splenectomy $(78 \%)$ did not differ significantly from five year survival after subtotal gastrectomy without splenectomy (69\%).

Influence of splenectomy on survival, stage for pathological stage - it is not surprising that five year survival should have been poorer among patients who underwent splenectomy than among patients who did not, because the pathological stage of the tumours in the first group tended to be more advanced (Table I). We therefore compared five year survival, after exclusion of postoperative deaths, of the two groups of patients, stage for pathological stage (Table V). Among patients with stage I tumours, five year survival was $91 \%$ in both groups: splenectomy had no influence on survival. That was true also for patients with stage II tumours, among whom $72 \%$ of those who had undergone gastrectomy without splenectomy and $69 \%$ of those who had undergone gastrectomy with splenectomy survived for five years. In stage III, however, a greater proportion of patients who had undergone gastrectomy without splenectomy survived for five years, than of patients who had undergone gastrectomy with splenectomy $(34 \%$ and $25 \%$ respectively, $\mathrm{p}<0.05$ ) (Fig 2).

Multivariate analysis - when all the factors listed in Table VI were analysed by Cox's proportional hazards model, metastasis to lymph nodes (hazard ratio 6.5 ) and depth of tumour penetration through the wall of the stomach

TABLE IV Causes of postoperative morbidity

\begin{tabular}{llcc}
\hline & $\begin{array}{l}\text { Gastrectomy with } \\
\text { splenectomy }\end{array}$ & $\begin{array}{l}\text { Total } \\
\text { gastrectomy }\end{array}$ & $\begin{array}{l}\text { Subtotal } \\
\text { gastrectomy }\end{array}$ \\
\hline Patients (n) & $76(\%)$ & $21(\%)$ & $98(\%)$ \\
Anastomotic leak $+1-$ sepsis & $13(17)$ & $1(5)$ & $7(7)$ \\
Sepsis & $11(14)$ & 0 & $2(2)$ \\
Haemorrhage & $2(3)$ & 0 & 0 \\
Pancreatic necrosis & $2(3)$ & 0 & 0 \\
Bile peritonitis & $1(1)$ & 0 & 0 \\
Necrosis of the transverse colon & $1(1)$ & 0 & 0 \\
Other & $1(1)$ & 0 & $6(6)$ \\
Total & $31(41)$ & $1(5)$ & $15(15)$ \\
\hline
\end{tabular}

(hazard ratio 3.3 ) were found, as expected, to be the most important predictors of survival. However, splenectomy was also found to be a significant predictor of poor survival (hazard ratio 1.5). No evidence was found that the extent of the gastric resection - total or subtotal - the seniority of the operating surgeon or the patient's age influenced survival.

\section{Discussion}

'The spleen is an important organ in the immunological defence of the host ...'

(Cooper and Williamson Br $\mathcal{F}$ Surg

1984; 71: 173-80)

The spleen itself is seldom affected by gastric cancer, though the lymph nodes in the hilum of the spleen are sometimes affected. In the past, the knowledge that these nodes may be involved by tumour led to the widespread, uncritical assumption that the spleen and its hilar nodes should always be removed en bloc with the stomach in the course of radical, potentially curative resection for carcinoma of the body, fundus, and cardia of the stomach. In the 1990s, because of the explosion of knowledge about the immunological functions of the spleen, which protect the host against infection and perhaps also against tumour micrometastases, such assumptions must be questioned. The burden of proof now lies with those who would remove the spleen, rather than those who would preserve it. That is, gastrectomy with splenectomy should not be accepted as the standard 'curative' operative procedure for gastric cancer until it can be shown that the addition of splenectomy confers significant advantage on the patient, either in terms of lower operative mortality or improved longterm survival.

\section{Morbidity and mortality}

We found that when the spleen was removed in the course of radical, potentially curative resection for gastric carcinoma, operative mortality was much higher than when the spleen was preserved $(12 \% \vee 2.5 \%, \mathrm{p}<0.05)$ and postoperative morbidity was much greater $(41 \% v$ $14 \%, \mathrm{p}<0.001)$. These figures are admittedly somewhat biased, because patients who underwent gastrectomy with splenectomy had more advanced disease, on average, than patients who underwent gastrectomy alone (Table I). Presumably, therefore, they underwent more extensive and hazardous operative procedures.

The results among patients who belonged to the same pathological stage and who either had, or had not, undergone splenectomy, were therefore examined. As Table $\mathrm{V}$ shows, the results were consistently better in patients in whom the spleen had been preserved. For example, in patients with stage I disease, both operative mortality $(14 \% \quad v \quad 2 \%)$ and postoperative morbidity $(37 \%$ v $15 \%)$ were considerably greater in patients who had undergone gastrectomy with splenectomy than in patients who had undergone gastrectomy alone. In stage III, operative mortality $(15 \% v 5 \%)$ and postoperative morbidity $(49 \% v 14 \%)$ were again found 


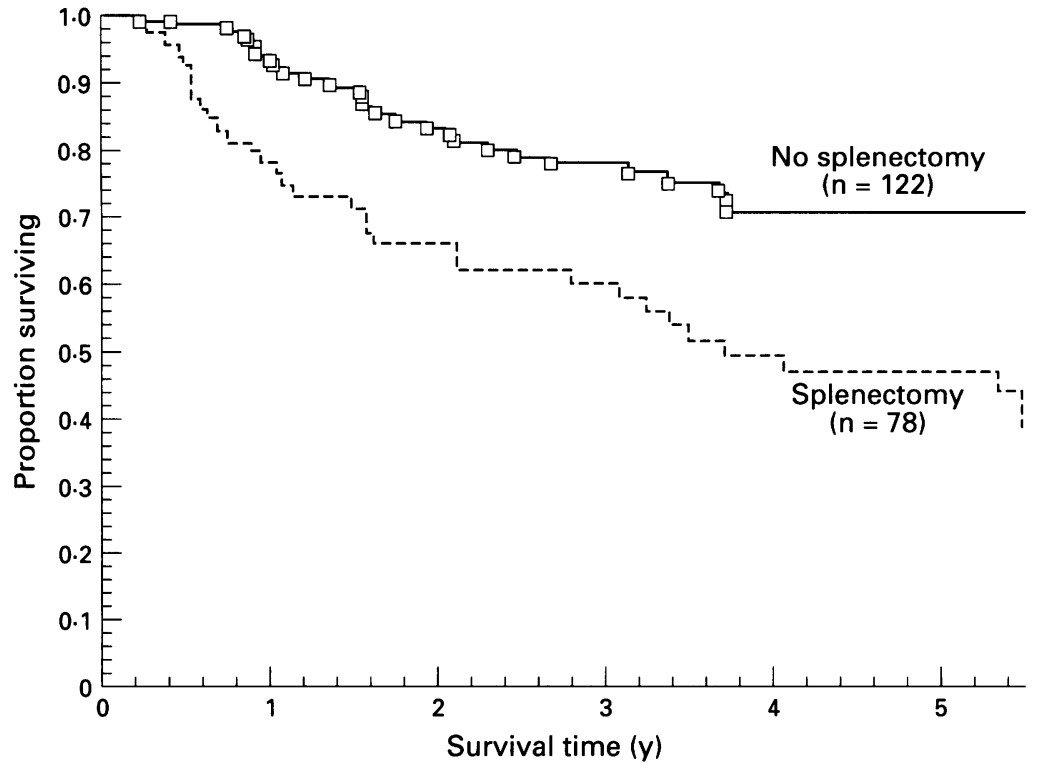

Figure 1: Cumulative survival curves of 195 patients with gastric cancer who underwent potentially curative gastrectomy with or without splenectomy, calculated by the life table method of Kaplan and Meier, after exclusion of operative deaths, ${ }^{\star} p<0 \cdot 01$.

to be greater in patients who had undergone splenectomy. Thus, within the same stage of disease, the addition of splenectomy led to an increase in operative mortality and postoperative morbidity. In patients with stage II disease, there was no appreciable difference between the two groups with respect to either operative mortality or postoperative morbidity.

It is quite conceivable that other factors such as improvements in anaesthetic technique, postoperative care, and better nutritional support have all contributed to the decrease in operative mortality and morbidity that was seen in the 1980 s, at a time when we were also striving to conserve the spleen and distal pancreas. ${ }^{7}$ While these factors undoubtedly contributed to safer surgery, however, we still feel that preservation of the spleen and pancreas made an important contribution to this reduction in overall operative mortality. In the latter years of this study (1985-1989) we performed 21 total

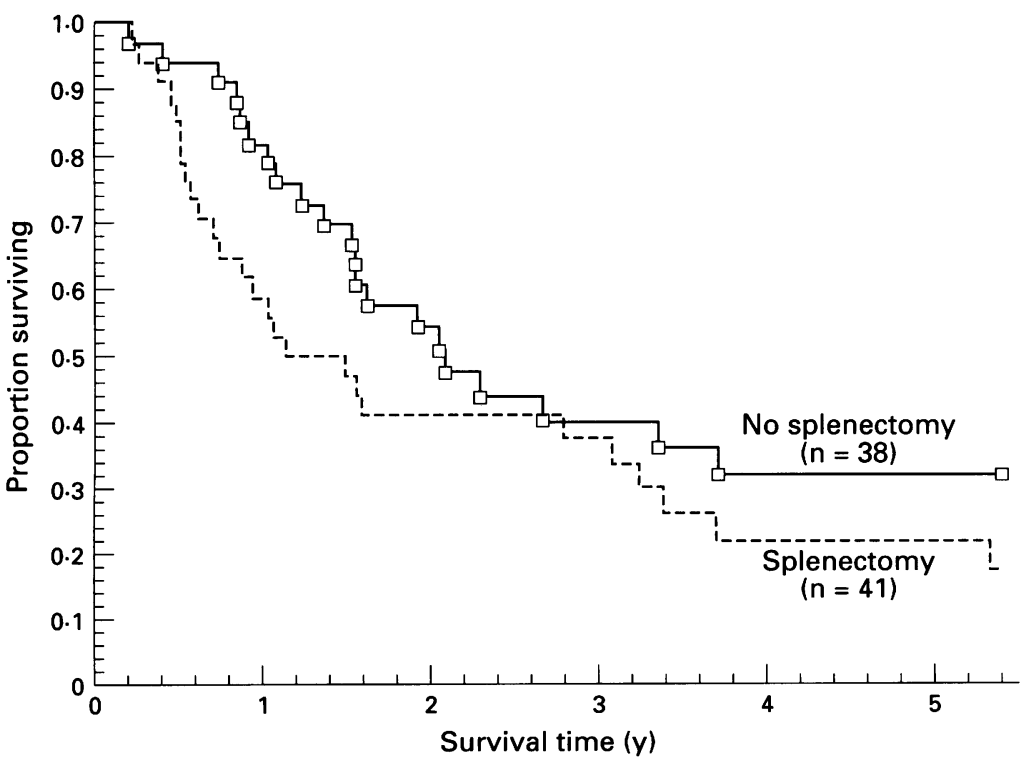

Figure 2: Cumulative survival curves of 78 patients with stage III gastric cancer, after curative resection with or without splenectomy, ${ }^{\star} p<0.05$. gastrectomies with preservation of the spleen and pancreas, and the operative mortality in this group of patients was $0 \%$ (Table II), compared with an overall operative mortality of $5 \%$ in the 1980 s.

The finding of increased mortality and morbidity after splenectomy in patients with gastric cancer is in agreement with the report by Brady et $a l^{8}$ that addition of splenectomy led to a higher incidence of infectious complications after gastrectomy. Incidental splenectomy in the course of operations for benign or malignant disease has been shown by several authors to be associated with increased operative mortality and postoperative morbidity. ${ }^{9-11}$ Furthermore, surgeons have shown great interest in preserving the spleen in the course of pancreatectomy, even when performed for carcinoma, to preserve the immunological functions of the spleen. ${ }^{12} 13$ Aldridge and Williamson ${ }^{12}$ found that there were fewer postoperative complications after pancreatectomy alone than after pancreatectomy with splenectomy.

In this study, 14 of 76 patients who underwent splenectomy also underwent distal pancreatectomy: three of them $(21 \%)$ died after operation. A similar finding has been reported recently by Mendes de Almeida et al ${ }^{14}$ : among 53 of their patients who underwent radical (R2) total gastrectomy for gastric cancer, there was no mortality among patients who underwent total gastrectomy alone, whereas among patients who underwent total gastrectomy combined with splenectomy and distal pancreatectomy, the death rate was $28 \%$. These authors attributed most of the increased mortality and morbidity to the addition of the pancreatic resection. Distal pancreatectomy exposes the patient to additional risk from leakage of pancreatic enzymes, fistulation, and sepsis. Hence pancreatectomy should be avoided in the course of operations for gastric cancer unless the tumour is actually penetrating directly into the pancreas. Suprapancreatic lymph nodes along the splenic artery can usually be removed without the need for pancreatic resection.

\section{Survival}

No evidence was found that removal of the spleen led to any increase in five year survival after potentially curative resection. We found, in fact, that patients who did not undergo splenectomy had a significantly better chance of surviving for five years than patients who underwent splenectomy $(71 \% \quad v \quad 45 \%$, $\mathrm{p}<0.01)$. When operative deaths were included in the calculations, the difference in five year survival between the two groups was even greater: $67 \%$ in the 'no splenectomy' group, compared with $39 \%$ in the splenectomy group $(\mathrm{p}<0.001)$.

Patients who underwent splenectomy had more advanced tumours, in general, than patients who did not undergo splenectomy. When allowance was made for tumour stage, the difference in survival between the splenectomy and non-splenectomy groups of patients largely disappeared. Five year survival in the 
TABLE V Influence of splenectomy on operative mortality, postoperative morbidity, and five year survival, when patients in the same pathological stage were compared

\begin{tabular}{|c|c|c|c|c|c|c|}
\hline \multirow[b]{2}{*}{ Operative procedure } & \multicolumn{2}{|l|}{ Stage I } & \multicolumn{2}{|l|}{ Stage II } & \multicolumn{2}{|l|}{ Stage III } \\
\hline & Splenectomy & $\begin{array}{l}\text { No } \\
\text { splenectomy }\end{array}$ & Splenectomy & $\begin{array}{l}\text { No } \\
\text { splenectomy }\end{array}$ & Splenectomy & $\begin{array}{l}\text { No } \\
\text { splenectomy }\end{array}$ \\
\hline $\begin{array}{l}\text { Patients (n) } \\
\text { Operative mortality (\%) } \\
\text { Postoperative morbidity (\%) }\end{array}$ & $\begin{array}{l}22 \\
3(14) \\
8(37)^{\star}\end{array}$ & $\begin{array}{l}55 \\
1(2) \\
8(15)^{\star}\end{array}$ & $\begin{array}{l}13 \\
0(0) \\
3(23)\end{array}$ & $\begin{array}{l}27 \\
0(0) \\
4(15)\end{array}$ & $\begin{array}{l}41 \\
6(15) \\
20(49) \dagger\end{array}$ & $\begin{array}{l}37 \\
2(5) \\
5(14) \dagger\end{array}$ \\
\hline $\begin{array}{l}\text { Five year survival (operative deaths } \\
\text { excluded) }(\%)\end{array}$ & 91 & 91 & 69 & 72 & $25^{\star}$ & $34^{\star}$ \\
\hline
\end{tabular}

${ }^{\star} \mathrm{p}<0.05,+\mathrm{p}<0.01$

two groups of patients was virtually identical in stages I and II, while in stage III disease, survival was only marginally better among patients who did not undergo splenectomy than among those who did (Table V). It is interesting, nevertheless, that as the disease became more advanced, some survival advantage was found to be associated with preservation of the spleen, whereas it might have been expected that the more extensive en bloc resection and lymphatic clearance made possible by splenectomy would have led to some increase in longterm survival in patients with stage II disease and, even more so, in stage III disease.

In summary, we found that splenectomy, with or without distal pancreatectomy, was associated with greatly increased operative mortality and postoperative morbidity, even in stage I disease, but did not lead to any increase in survival, when patients with the same pathological stage were compared (Table V). Hence we conclude that the spleen should be preserved in the course of radical, potentially curative operations for gastric cancer.

Previous clinical studies of the effect of splenectomy on survival after gastrectomy for gastric cancer have reported broadly similar findings. In some, no evidence was found that splenectomy increased survival, 81516 while in others splenectomy diminished the likelihood of survival. ${ }^{17-19}$ For example, Yoshino et al ${ }^{19}$ found that five year survival was $47 \%$ after radical total gastrectomy and splenectomy, compared with $61 \%$ after total gastrectomy alone, among patients who underwent resection for locally advanced tumours of the proximal stomach. Likewise, Koga et al ${ }^{17}$ found that five year survival in patients with stage III disease was greater among those who underwent gastrectomy without splenectomy than among those who underwent gastrectomy with splenectomy ( $41 \% v 20 \%$ respectively). In this

TABLE VI Factors analysed by Cox's proportional hazards model

\begin{tabular}{lc}
\hline Independent variables & $\begin{array}{l}\text { Hazards } \\
\text { ratio }\end{array}$ \\
\hline Nodal status & \\
$\mathrm{N}-\mathrm{ve} v \mathrm{~N}+\mathrm{ve}$ & $6 \cdot 5$ \\
$\mathrm{~N} 0 v \mathrm{~N} 1$ & $3 \cdot 9$ \\
$\mathrm{~N} 1 v \mathrm{~N} 2$ & $3 \cdot 9$ \\
$\mathrm{~N} 0 v \mathrm{~N} 2$ & $15 \cdot 0$ \\
Depth of tumour penetration (T1 $v$ T3) & $3 \cdot 3$ \\
Splenectomy $v$ no splenectomy & $1 \cdot 5$ \\
Pancreatectomy $v$ no pancreatectomy & $\mathrm{NS}$ \\
Extent of gastric resection: (total $v$ subtotal & $\mathrm{NS}$ \\
gastrectomy) & $\mathrm{NS}$ \\
Grade of operating surgeon (consultant $v$ senior & $\mathrm{NS}$ \\
registrar) & \\
Age of patient & \\
\hline
\end{tabular}

study, also, we found that patients with stage III tumours had a better chance of survival if the spleen was preserved. In patients with stage I and II disease, we found that five year survival was much the same, whether or not the spleen had been removed, which is in agreement with previous reports. ${ }^{8}{ }^{15-17}$

An adverse effect of splenectomy on survival has also been reported in patients with colorectal cancer who have lymph nodes affected with tumour. For example, Davis et al ${ }^{20}$ found that in patients who had undergone potentially curative resection for Dukes's C cancer of the colon, splenectomy was associated with decreased five year survival: $52 \%$ without splenectomy compared with only $19 \%$ if splenectomy had been performed. In that study, however, blood transfusion requirements among patients who had undergone splenectomy were greater than in those who had not, and this could have influenced survival adversely in the splenectomy group. Unfortunately, information on the requirement for blood transfusion of the patients in our study was insufficient to allow us to assess the influence of this factor on survival.

Our study differs from previous reports in that we found by multivariate analysis that splenectomy was an independent predictor of poor outcome, in the form of death from recurrent cancer (hazard ratio 1.5). Admittedly, the adverse effect of splenectomy on survival was comparatively weak compared with the profound influence exerted by depth of tumour penetration and the presence of lymph node metastases (Table VI), as Maruyama ${ }^{21}$ and many others have shown previously. While accepting that this analysis has all the inherent problems associated with retrospective studies and that the two groups of patients were not matched prospectively stage for pathological stage, we have certainly failed to show that removal of the spleen confers any benefit on the patient.

\section{Theoretical considerations in favour of and against splenectomy}

Why then has it been accepted for so long that the spleen (and sometimes the tail of the pancreas) should be included in radical resections for gastric cancer, at least for tumours that are situated in the body or fundus of the stomach? As long ago as 1941,22 the nodes in the hilum of the spleen were reported to be affected by metastatic spread from gastric cancer. Japanese and German authors have emphasised how important it is to remove both 
the first and second tier of lymph nodes in the course of potentially curative resection for gastric cancer. ${ }^{32324}$ The nodes at the hilum of the spleen, however, are usually $\mathrm{N} 2$ nodes (nodes of the second tier), unless the tumour is located on the greater curvature of the stomach, near the splenic hilum. In this study, $87 \%$ of patients with $\mathrm{N} 2$ nodal involvement had primary tumours that had also penetrated through the serosa (T3), and few patients with such T3N2 tumours survive for five years, even after the most radical types of gastric resection. ${ }^{25}$

It is patients whose cancers are located in the proximal third of the stomach who have the greatest probability of having affected lymph nodes in the hilum of the spleen. Even among these patients, however, only $3 \%$ of patients with T2 tumours and $13 \%$ of patients with T3 tumours have affected splenic hilar nodes, though when the tumour is on the greater curvature of the stomach, close to the splenic hilum, $26 \%$ of patients have positive splenic hilar nodes. ${ }^{26}$ Thus, most patients with carcinoma of the stomach do not have splenic hilar lymph nodes that are affected with tumour, and when these nodes are affected, the tumour is usually incurable for other reasons, such as the presence of many other positive $\mathrm{N} 2$ or N3 nodes, an advanced $\mathrm{T}$ stage, or distant micrometastases in peritoneum, liver or elsewhere. Hence, the proportion of cases in which the removal of affected splenic hilar nodes could be regarded as specifically vital - a matter of life or death - is very small, accounting, in our opinion, for no more than $1 \%$ of all cases of gastric cancer.

Four other factors could account for the lack of any beneficial effect, and even for the slightly detrimental effect, of splenectomy seen in this study. Firstly, sepsis resulting from pneumococcal and other types of infection occurs after splenectomy, though it is uncommon in adults who are otherwise healthy. ${ }^{27-30}$ Patients who have a coexisting condition, however, such as malignant disease are at substantially greater risk of sepsis after splenectomy. Furthermore, incidental splenectomy in non-malignant conditions has been shown to be associated with an increase in mortality from infectious causes. ${ }^{31}$ This association of splenectomy with overwhelming sepsis has been linked to changes in the patient's humoral immune system. The permanent decrease in circulating antibody concentrations that has been reported after splenectomy and reduced response to pneumococcal antigens may explain the increased incidence of septic complications. ${ }^{32}$ Secondly, it has been shown by in vivo and in vitro studies that the ability of hepatic Kupffer cells to opsonise particulate matter is reduced after splenectomy and their ability to respond to an antigenic challenge is diminished. ${ }^{33} 34$ Aldridge et al ${ }^{33}$ showed a reduction in uptake of Escherichia coli by Kupffer cells after splenectomy, with a consequent increase in deposition of the organisms in the pulmonary vasculature. Thirdly, several studies have reported an increased risk of death from ischaemic heart disease and pulmonary embolism after splenectomy. ${ }^{31} 35$ Pimpl et al ${ }^{35}$ showed that the risk of thromboembolic complications was considerably greater in patients who underwent splenectomy, whether malignant disease was present or not. The increased risk of thromboembolism after splenectomy is thought to result from greater blood viscosity and to an increase in the platelet count. ${ }^{36}$ Finally, longterm depression of $T$ cell proliferation, a measure of the cell mediated immune system, has been shown in patients after splenectomy. ${ }^{37}$ This impaired proliferative response to mitogens such as phytohaemagglutinin may point to a more general impairment of patients' immune system after splenectomy, which could diminish their ability to lyse tumour micrometastases. The presence of the spleen has been shown to be essential if immunomodulation with the streptococcal preparation, OK-432, is to be effective when used as adjuvant therapy in gastric cancer. ${ }^{38}$ Precisely how OK-432 acts and why the spleen should be necessary for its activity are unclear. It may be no coincidence, however, that $\mathrm{OK}-432$ is a streptococcal derivative, as the spleen is essential for the immune response to streptococcal infection in humans.

In summary, an important indictment of surgery for gastric cancer in Britain is that the operative mortality is still too high, though some improvement has been noted in recent years. ${ }^{39}$ In the largest survey of gastric cancer ever undertaken in Britain, ${ }^{40}$ operative mortality after potentially curative resection was $16 \%$, while after palliative resection the mortality was $25 \%$. Radical (R2) clearance of lymph nodes is important for the survival of patients with stage II and IIIa disease who undergo potentially curative resection, as Japanese $^{2124}$ and German ${ }^{25}$ surgeons have shown. Although in expert hands such radical resections can be accomplished with an operative mortality of two to five per cent, ${ }^{72125}$ prospective randomised trials in the Netherlands ${ }^{41}$ and in the United Kingdom ${ }^{42}$ suggest that they may be associated with increased postoperative morbidity and mortality, and they might be rendered safer if the spleen and tail of pancreas were preserved. To reduce the operative mortality from more than $10 \%$ to less than $5 \%$ would, in itself, be an important contribution to surgery for gastric cancer in Britain, because it would permit some patients with early gastric cancer or with stage I or II disease, who are currently dying needlessly within 30 days of operation, to survive in the long term. This point is illustrated by the deaths, in this study, of three patients with stage I disease (Table III) after total gastrectomy with splenectomy and distal pancreatectomy who would probably have survived the operative procedure and been cured if the spleen and pancreas had been preserved.

The distribution of cancers within the stomach itself is said to be changing in Western countries, a greater proportion of them occurring in the proximal stomach and a smaller proportion in the distal stomach. ${ }^{434}$ This brings into sharp focus the debate about 
whether or not the spleen should be included in the en bloc resection. On the basis of our findings, the performance of routine splenectomy in cases of gastric cancer that require total gastrectomy cannot be recommended, except in patients in whom the tumour lies close to the splenic hilum or even invades it directly. Likewise, if the tumour has penetrated through the posterior wall of the stomach directly into the pancreas, splenectomy must be performed in conjunction with distal pancreatectomy, if potentially curative resection is still feasible. In most patients with 'curable' gastric cancer, however, total or subtotal gastrectomy combined with radical, R2, lymphadenectomy is compatible with preservation of the entire pancreas and the spleen.

1 MacFarlane JK, Ryall RD, Heald RJ. Mesorectal excision for rectal cancer. Lancet 1993; 341: 457-60.

$2 \mathrm{McArdle} C S$, Hole D. Impact of variability among surgeons on post-operative morbidity and mortality and ultimate survival. $B M \mathcal{F}$ 1991; 302: 1501-5.

3 Japanese Research Society for Gastric Cancer. The general rules for the gastric cancer study in surgery and pathology: Part I. Clinical classification. $f_{p n} \mathcal{f}$ Surg 1981; 11: 127-39.

4 Kennedy BJ. The unified international gastric cancer staging classification. Scand $\mathcal{F}$ Gastroenterol 1987; 22 (suppl 133): $11-3$.

5 Kaplan EL, Meier P. Nonparametric estimation from incomplete observations. $\mathcal{F}$ Am Stat Assoc 1958; 6: 371-5

6 Cox DR. Regression models and life tables. $\mathcal{f} R$ Statist Soc $B$ 1972; 34: 187-220.

7 Sue-Ling HM, Johnston D, Martin IG, Dixon MF, Lansdown MRJ, McMahon MJ, et al. Gastric cancer: a curable disease in Britain. $B M \mathcal{F}$ 1993; 307: 591-6.

8 Brady MS, Rogatko A, Dent LL, Shiu MH. Effect of splenectomy on morbidity and survival following curative gastrectomy for gastric carcinoma. Arch Surg 1991; 126: 359-64.

9 Danforth DN, Thorbjarnson B. Incidental splenectomy: a review of the literature and the New York hospital review of the literature and the New

10 Zieminski JM, Rudowski WJ, Jaskowiak W, Rusiniak L Scharf R. Evaluation of early postsplenectomy complicaScharf R. Evaluation of early postsplenectom

11 Carlstedt A, Tholin B. Infectious complications after splenectomy. Acta Chir Scand 1984; 150: 607-10.

12 Aldridge MC, Williamson RCN. Distal pancreatectomy with and without splenectomy. Br f Surg 1991; 78: 976-9.

13 Warshaw AL. Conservation of the spleen with distal pancreatectomy. Arch Surg 1988; 123: 550-3.

14 Mendes de Almeida JC, Bettencourt A, Santos Costa C, Mendes de Almeida JM. Role of splenectomy and distal pancreatectomy in curative surgery for gastric cancer pancreatectomy in curative surgery for gastr.

15 Suehiro S, Nagasue N, Ogawa Y, Sasaki Y, Hirose S, Yukaya H. The negative effect of splenectomy on the 6 prognosis of gastric cancer. Am f Surg 1984; 148: 645-8. Korenaga D, Sugimachi K. Splenectomy does not correlate with length of survival in patients undergoing total curative gastrectomy for gastric carcinoma. Cancer 1991 67: 3006-9.

17 Koga S, Kaibara N, Kimura O, Nishidoi H, Kishimoto H. Prognostic significance of combined splenectomy or pancreaticosplenectomy in total and proximal gastrectomy for gastric cancer. Am $\mathcal{f}$ Surg 1981; 148: 546-50.

18 Sugimachi K, Kodama Y, Kumashiro R, Kanematsu T, Noda $S$, Inokuchi $K$. Critical evaluation of prophylactic splenectomy in total gastrectomy for stomach carcinoma. Gann 1980; 71: 704-9.
19 Yoshino K, Haruyama K, Nakamura S, Matsumoto S, Yamada Y, Isobe $\mathrm{K}$, et al. Evaluation of splenectomy for gastric cancer. Nippon Gann Chiryo Gakkai Shi 1979; 12: gastric

20 Davis CJ, Ilstrup DM, Pemberton JH. Influence of splenectomy on survival rate of patients with colorectal cancer. Am $\mathcal{F}$ Surg 1988; 155: 173-8.

21 Maruyama K. The most important prognostic factors for gastric cancer patients. Scand $\mathcal{f}$ Gastroenterol 1987; 22 (suppl 133): 63-8.

22 Coller FA, Kay EB, MacIntyre RS. Regional lymphatic metastases of carcinoma of stomach. Arch Surg 1941; 43: 748-61.

23 Meyer HJ, Jahne J, Wilke H, Pichlmayr R. Surgical treatment of gastric cancer: retrospective survey of 1704 operated
cases with special reference to total gastrectomy as the cases with special reference to total gastrectomy as the
operation of choice. Semin Surg Oncol 1991; 7:356-64.

24 Kodama Y, Sugimachi K, Soejima K, Matsusaka T, Inokuchi $\mathrm{K}$. Evaluation of extensive lymph node dissection for carcinoma of the stomach. World $\mathcal{f}$ Surg $1981 ; 5$ : 241-8.

25 Siewert JR, Bottcher K, Roder JD, Busch R, Hermanek P, Meyer HJ, and the German Gastric Carcinoma Study Group. Prognostic relevance of systematic lymph node dissection in gastric carcinoma. $\mathrm{Br} \mathcal{F}$ Surg 1993; 80: 1015-8.

26 Maruyama K. Surgical treatment and end results of gastric cancer. Surgical handbook. Tokyo: Department of Surgery, cancer. Surgical handbook. Tokyo:

27 Holdsworth RJ, Irving AD, Cuschieri A. Postsplenectomy sepsis and its mortality rate: actual versus perceived risk. Br $\mathcal{F}$ Surg 1991; 78: 1031-8.

28 Cullingford GL, Watkins DN, Watts ADJ, Mallon DF Severe late postsplenectomy infection. Br f Surg 1991; 78: 716-21.

29 Schwartz PE, Sterioff S, Mucha P, Melton JL, Offord KP Postsplenectomy sepsis and mortality in adults. $\mathfrak{F} A M A$ 1982; 248: 2279-83.

30 Morris DH, Bullock FD. The importance of the spleen in resistance to infection. Ann Surg 1919; 70: 513-21.

31 Robinette CD, Fraumeni JF. Splenectomy and subsequent mortality in veterans of the 1939-45 war. Lancet 1977; ii: mortality

32 Di Padova F, Durig M, Wadstrom J, Harder F. Role of the spleen in immune response to polyvalent pneumococcal vaccine. $B M \mathcal{F} 1983$; 287: 1829-32.

33 Aldridge MC, Cheslyn-Curtis S, Chadwick SJD, Dudley HAF. Splenic reticuloendothelial function following surgery [Äbstract]. Br $\mathcal{F}$ Surg 1989; 76: 647.

34 Billiar TR, West MA, Hyland BJ, Simmons RL Splenectomy alters kupffer cell response to endotoxin. Arch Surg 1988; 123: 327-32.

35 Pimpl W, Dapunt O, Kaindl H, Thalhamer J. Incidence of septic and thromboembolic related deaths after splenectomy in adults. Br f Surg 1989; 76: 517-21.

36 Robertson DAF, Simpson FG, Losowsky MS. Blood viscosity after splenectomy. $B M \mathcal{F} 1981 ; 283$ : 573-5.

37 Downey EC, Shackford SR, Fridlund PH, Ninnemann JL Long term depressed immune function in patients splenectomised for trauma. I Trauma 1987; 27: 661-3.

38 Kyoto Research Group for Digestive Organ Cancer. A comprehensive multi-institutional study on postoperative adjuvant immunotherapy with oral streptococcal preparation OK-432 for patients with gastric cancer. Ann Surg tion OK-432 for pat

39 Akoh JA, Sedgwick DM, Macintyre IMC. Improving results in the treatment of gastric cancer: an 11-year audit. $B r \mathcal{F}$ Surg 1991; 78: 349-51.

40 Allum WH, Powell DJ, McConkey CC, Fielding JWL Gastric cancer: a 25 year review. Br $\mathcal{F}$ Surg 1989; 76: 535-40.

41 Bonenkamp J, Bunt AMG, van der Velde CJH, Dutch Gastric Cancer Group. Gastric cancer: a prospective randomised trial of surgical treatment. Onkologie 1992; 15: $133-8$.

42 Cuschieri A. Gastrectomy for gastric cancer: definitions and objectives. Br F Surg 1986; 73: 513-4.

43 Blot WJ, Devesa SS, Kneller RW, Fraumeni JF. Rising incidence of adenocarcinoma of the esophagus and gastric incidence of adenocarcinoma of the

44 Powell J, McConkey CC. Increasing incidence of adenocarcinoma of the gastric cardia and adjacent sites. Brf $\mathcal{F}$ Cancer 1990; 59: 440-3. 